\title{
Evaluation of Intravenous Paracetamol Administration on Postoperative Pain in Patients Undergoing Laparoscopic Cholecystectomy
}

\section{Abdalssalam Abdelhamid Alahresh ${ }^{1}$, Azab Elsayed Azab ${ }^{2 *}$, Abdelhamid sultan mobarak ${ }^{3}$ Bushra Al-mabruk ${ }^{4}$, Hanaa fawze Khafaji ${ }^{5}$, Malak musa abozed ${ }^{6}$, Masara faraj beleid ${ }^{7}$, Omaima Al-hadi jogdam ${ }^{8}$}

\author{
${ }^{1}$ Department of Pathology, Faculty of Medicine, Sabratha University. \\ ${ }^{2}$ Department of Physiology, Faculty of Medicine, Sabratha University. \\ ${ }^{3-8}$ Department of Anesthesia and Intensive Care, Faculty of Medical Technology-Surman, Sabratha University. \\ *Corresponding Author: Azab Elsayed Azab, Department of Physiology, Faculty of Medicine, Sabratha University, \\ Sabratha, Libya.
}

Abstract

Background: Laparoscopic cholecystectomy has rapidly become the procedure of choice for routine gallbladder removal and is currently the most commonly performed major abdominal procedure in Western countries. Paracetamol is a medication used to treat pain and fever. It is typically used for mild to moderate pain relief. Also it is used for severe pain, such as cancer pain and pain after surgery, in combination with opioid pain medication.

Objectives: The aim of the present study was to evaluate the effects of intravenous paracetamol treatment on early postoperative period analgesia after laparoscopic cholecystectomy.

Subjects and Methods: Those patients were attending the general surgical unit in Sabratha Hospital. We conducted a case-control study of 20 patients underwent laparoscopic cholecystectomy as control group (aged 25 to 55 years; 13 males, 7 females) and their nearest-aged paracetamol group (aged 24 to 55 years; 14 males, 6 females). was used to assess severity of pain in all cases and controls. Pain evaluation was performed every 15 minutes after pain control was obtained. Results: There was a significant difference between cases and controls regarding all scores of Verbal Rating Scales. The verbal evaluation scores of the paracetamol group were significantly lower than the control group.

Conclusion: It can be concluded that paracetamol is effective postoperative analgesia. It is the drug of choice in patients that cannot be treated with non-steroidal anti-inflammatory drugs. Pre-operative administration of paracetamol supports effective and faster recovery. Anticipatory guidance should be provided to encourage to use paracetamol as postoperative analgesia. Further studies are needed to clarify the postoperative recovery characteristics by Modified Aldrete's Scoring System.

Keywords: Intravenous, Paracetamol, Laparoscopic cholecystectomy, Postoperative pain, Pain evaluation, Verbal evaluation scores

\section{INTRODUCTION}

Laparoscopic cholecystectomy has rapidly become the procedure of choice for routine gallbladder removal and is currently the most commonly performed major abdominal procedure in Western countries [1]. A National Institutes of Health consensus statement in 1992 stated that laparoscopic cholecystectomy provides a safe and effective treatment for most patients with symptomatic gallstones and has become the treatment of choice for many patients [2]. Laparoscopic cholecystectomy 
Evaluation of Intravenous Paracetamol Administration on Postoperative Pain in Patients Undergoing Laparoscopic Cholecystectomy

decreases postoperative pain, decreases the need for postoperative analgesia, shortens the hospital stay from 1 week to less than 24 hours, and returns the patient to full activity within 1 week (compared with 1 month after open cholecystectomy) [3, 4]. The general indications for laparoscopic cholecystectomy are the same as those for the corresponding open procedure. Although laparoscopic cholecystectomy was originally reserved for young and thin patients, it now is also offered to elderly and obese patients

Cholecystectomy is not indicated in most patients with asymptomatic (silent) gallstones, because only 2-3\% of these patients go on to become symptomatic each year. For an accurate determination of the indications for elective cholecystectomy, the risk posed by the operation (with individual patient age comorbid factors taken into account) must be weighed against the risk of complications and death if the operation is not done [5].

Patients who are immunocompromised, are awaiting organ allotransplantation, or have sickle cell disease are at higher risk for the development of complications and should be treated irrespective of the presence or absence of symptoms [6].

Acute cholecystitis, if diagnosed within 72 hours after symptom onset, can and usually should be treated laparoscopically. Beyond this 72-hour period, inflammatory changes in surrounding tissues are widely believed to render dissection planes more difficult. This may, in turn, increase the likelihood of conversion to an open procedure to $25 \%$ [7-9].

Once the clinical signs of mild-to-moderate biliary pancreatitis have resolved, laparoscopic cholecystectomy can be safely performed during the same hospitalization [10].

Laparoscopic cholecystectomy is a safe and effective treatment for most children diagnosed with biliary disease. Although it takes longer to perform than open cholecystectomy does, it results in less postoperative narcotic use and a shorter hospital stay, as has been the case in the adult literature. ${ }^{(13)}$ Laparoscopic cholecystectomyin safe in many patients with cirrhosis. The laparoscopic approach should be considered the procedure of choice in the patients with Child class $A$ and $\mathrm{B}$ cirrhosis and symptomatic gallstone disease. Patients with Child class C cirrhosis who present with symptomatic cholelithiasis or cholecystitis should be considered for medical management if they are transplant candidates $[11,12]$.

The presence of diabetes mellitus, in and of itself, does not confer sufficient risk to warrant prophylactic cholecystectomy in asymptomaticindividuals. Itshould be kept in mind, however, that acute cholecystitis in a patient with diabetes is associated with a significantly higher frequency of infectious complications, such as sepsis [9].

Laparoscopic cholecystectomy remains an extremely safe procedure, with a mortality of $0.22-0.4 \%$ [13, 14]. Major morbidity occurs in approximately $5 \%$ of patients [15]. Complications include Trocar/Veress needle injury, Hemorrhage, Post cholecystectomy syndrome, CBD injury or stricture, Wound infection or abscess, Gallstone spillage, and Deep vein thrombosis

Since its clinical introduction in 1955, acetaminophen ( $\mathrm{N}$-acetyl-p-aminophenol; APAP; paracetamol) has become the most widely used analgesic-antipyretic in the United States [16]. Acetaminophen is a component of hundreds of over-the-counter and prescription medications used worldwide. Paracetamol is a medication used to treat pain and fever. It is typically used for mild to moderate pain relief [17]. Paracetamol is also used for severe pain, such as cancer pain and pain after surgery, in combination with opioid pain medication [18].

Paracetamol is generally safe at recommended doses $[18,19]$. The recommended maximum daily dose for an adult is three to four grams [19]. Higher doses may lead to toxicity, including liver failure. Serious skin rashes may rarely occur [17].

Pain is an unpleasant sensory and emotional experience associated with actual or potential tissue damage. Undergoing treatment (such as surgical procedures) may result in the occurrence of postoperative pain, and this triggers biochemical and physiological stress responses [20]. Pain is a major public health issue throughout the world and represents a major clinical, social, and economic problem [21]. Postsurgical pain is normally perceived as nociceptive pain. Surgical trauma has been known to induce central and peripheral sensitization and hyperalgesia, which in untreated cases could lead to chronic postoperative pain after surgery [22]. Proper

Archives of Anesthesiology V3 . I2 . 2020 
Evaluation of Intravenous Paracetamol Administration on Postoperative Pain in Patients Undergoing Laparoscopic Cholecystectomy

pain management, particularly postoperative pain management, is a major concern for clinicians as well as for patients undergoing surgery. Patients commonly enquire about the level of pain they may experience after an operation. Postoperative pain not only affects the patients' operative outcome, well-being, and satisfaction from medical care, but also directly affects the development of tachycardia, hyperventilation, decreases in alveolar ventilation, transition to chronic pain, poor wound healing, and insomnia, which in turn may impact the operative outcomes $[23,24]$. Individual variations in the response to pain are influenced by the genetic makeup, cultural background, age, and gender [25]. The practice of modern anesthesiology has been developed from intraoperative period into perioperative period. Postoperative pain management is one of the most important components of adequate postsurgical patient's care [26]. Pain during and after surgery can lead to sensitization and consequently oversensitivity to pain, it can also transform postoperative acute pain into chronic pain [27]. Effective postoperative pain control is important, especially with the initiation of physiotherapy and early ambulation, which hastens recovery and reduces hospital length of stay [28]. The use of opioid drugs for the pain control during and after surgery is a common procedure in anesthesia [29]. However, the use of these medications is associated with side effects such as nausea, vomiting, sedation, and respiratory depression. Prescribed method for reducing and minimizing opioid side effects is concomitant administration of a nonopioid analgesic [30]. The decision to mix drugs should not be made without the knowledge of their compatibility. Incompatibility problems are more likely to arise when small concentrated volumes are mixed in a syringe rather than in the large volume of infusion bag [31]. Some of these medications are nonsteroidal anti-inflammatory drugs, including aspirin and Acetaminophen (Paracetamol). Primary mechanism of these analgesic drugs is to inhibit the cyclooxygenase and prostaglandin synthesis which is considered as an important environmental factor in the prevention of hypersensitivity and pain [29].

\section{ОВJECTIVES}

The aim of this study was to evaluate the effects of intravenous paracetamol treatment on early postoperative period analgesia after laparoscopic cholecystectomy.

\section{SubJeCtS AND Methods}

The study was included 2 groups underwent:

Group I (paracetamol group): 20 patients underwent laparoscopic cholecystectomy. In this group, $1 \mathrm{~g}$ paracetamol was given to the patients intravenously after intubation before start of the surgery in 15 minutes.

Group II (control group): 20 patients underwent laparoscopic cholecystectomy. The $100 \mathrm{ml} \quad 0.9 \%$ $\mathrm{NaCl}$ were infused intravenously for this group in 15 minutes instead of paracetamol.

Inclusion criteria were the age above 18 years, agreed about they have understood the verbal and visual analog pain evaluation scales, and normal neurological examinations.

Exclusion criteria were the patients who take analgesics or alcohol chronically, body mass index higher than 35 , who have hypersensitivity to the drugs that are used in the study, who have diminished liver and kidney functions, and chronic or current illness (e.g; DM, HTN).

After approval of the medical ethical committee and a verbal consent taken from all patients, they were assessed thoroughly by Complete history taking with special emphasis on Age (y), and gender (female/ male), Full clinical examination, Pain assessment using a Verbal Rating Scale [32, 33].

In a Verbal Rating Scale (VRS) adjective is used to describe different levels of pain. The respondent is asked to mark the adjective which fits best to the pain intensity. As in the VAS, two endpoints such as 'no pain at all' and 'extremely intense pain' should be defined. Between these extremes, different adjectives which describe different pain-intensity levels are placed in the order of pain severity ( 0 =painless, $1=$ very mild, $2=$ moderate, and $3=$ severe) [32].

\section{RESULTS}

Table (1) and figure (1) show comparison between the two studied groups regarding demographic data, it demonstrated that:

The study has been conducted on 40 patients underwent laparoscopic cholecystectomy attending the Sabratha hospital. The age in paracetamol' group 
Evaluation of Intravenous Paracetamol Administration on Postoperative Pain in Patients Undergoing Laparoscopic Cholecystectomy

ranged 24-55 years and in control group ranged 2555 years. There was no significant difference between the studied groups according to age

In paracetamol group, males were 14 and females were 6, in control group, males were 13 and females were 7. There was no significant difference between the studied groups according to sex.

Table 1. Comparison between the studied groups according to gender

\begin{tabular}{|l|c|c|}
\hline Groups Gender & $\begin{array}{c}\text { Control } \\
(\mathbf{n = 2 0 )}\end{array}$ & $\begin{array}{c}\text { Paracetamol } \\
(\mathbf{n = 2 0 )}\end{array}$ \\
\hline Male & 13 & 14 \\
\hline Female & 7 & 6 \\
\hline
\end{tabular}

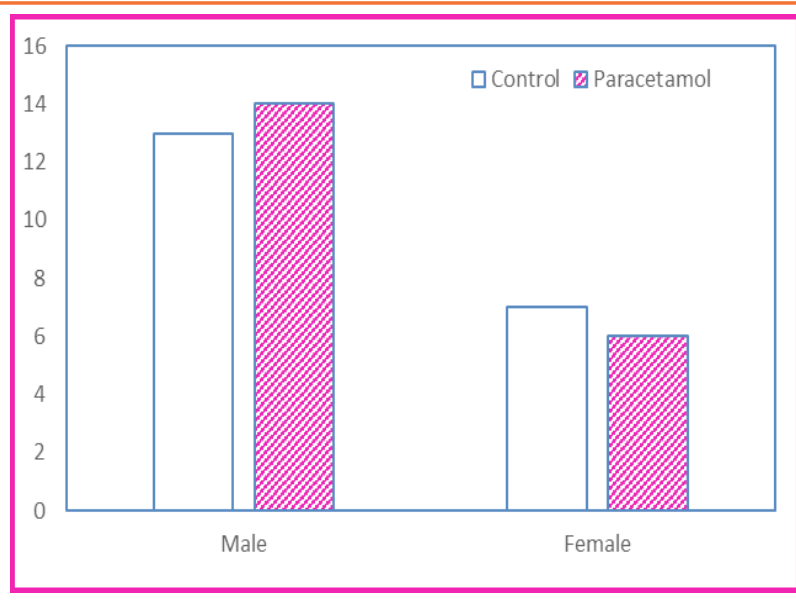

Figure 1. Distribution of control and paracetamol groups according to gender

Table 2. Distribution of studied paracetamol and control groups according to verbal pain scores

\begin{tabular}{|c|c|c|c|c|c|c|c|c|}
\hline \multirow{3}{*}{ Pt. No } & \multicolumn{8}{|c|}{ Verbal Pain Scores } \\
\hline & \multicolumn{2}{|c|}{5 minutes } & \multicolumn{2}{|c|}{15 minutes } & \multicolumn{2}{|c|}{30 minutes } & \multicolumn{2}{|c|}{60 minutes } \\
\hline & Paracetamol & Control & Paracetamol & Control & Paracetamol & Control & Paracetamol & Control \\
\hline 1 & 1 & 2 & 1 & 3 & 2 & 3 & 2 & 3 \\
\hline 2 & 1 & 1 & 3 & 2 & 3 & 3 & 2 & 2 \\
\hline 3 & 2 & $\mathbf{0}$ & $\mathbf{0}$ & 1 & 2 & 2 & 2 & 3 \\
\hline 4 & 1 & $\mathbf{0}$ & 2 & 2 & 3 & 3 & 2 & 2 \\
\hline 5 & $\mathbf{0}$ & 2 & 2 & 3 & 3 & 3 & $\mathbf{0}$ & 3 \\
\hline 6 & $\mathbf{0}$ & 2 & 3 & 3 & 1 & 3 & 2 & 3 \\
\hline 7 & 1 & 2 & 2 & 3 & 2 & 3 & 1 & 3 \\
\hline 8 & 1 & 1 & 1 & 2 & 1 & 1 & 2 & 2 \\
\hline 9 & 1 & 2 & 1 & 3 & 2 & 2 & 3 & 3 \\
\hline 10 & 2 & 2 & 3 & 3 & 2 & 2 & 1 & 3 \\
\hline 11 & 1 & 3 & 3 & 3 & 3 & 3 & 2 & 2 \\
\hline 12 & 3 & 2 & 3 & 3 & 1 & 3 & $\mathbf{0}$ & 3 \\
\hline 13 & $\mathbf{0}$ & $\mathbf{0}$ & $\mathbf{0}$ & 1 & 2 & 2 & 3 & 3 \\
\hline 14 & 1 & $\mathbf{0}$ & 3 & 2 & 2 & 3 & 2 & 2 \\
\hline 15 & $\mathbf{0}$ & 1 & 2 & 2 & 1 & 3 & 3 & 3 \\
\hline 16 & 2 & 2 & 1 & 3 & 1 & 3 & $\mathbf{0}$ & 3 \\
\hline 17 & 1 & 2 & 1 & 3 & 3 & 3 & 3 & 3 \\
\hline 18 & 0 & 1 & 2 & 2 & 3 & 3 & 1 & 3 \\
\hline 19 & 2 & 1 & 2 & 2 & 3 & 3 & $\mathbf{0}$ & 3 \\
\hline 20 & $\mathbf{0}$ & 3 & 1 & 3 & 3 & 3 & $\mathbf{0}$ & 3 \\
\hline Total & 20 & 29 & 36 & 49 & 43 & 54 & 31 & 55 \\
\hline Percent (\%) & 40.8 & 59.2 & 42.4 & 57.6 & 44.3 & 55.7 & 36.1 & 63.9 \\
\hline
\end{tabular}

(Pain-intensity levels: $0=$ painless, $1=$ =very mild, 2=moderate, and 3=severe)

\section{Pain Assessment Using a Verbal Rating Scale}

Postoperative pain was evaluated by Verbal Rating Scale.

Table (1) shows distribution of studied groups according to severity of pain at different time. Comparisons of pain scores of the paracetamol and control groups are outlined in Table (1) and figure (2). There was a statistically significant difference between paracetamol and control groups. 
Evaluation of Intravenous Paracetamol Administration on Postoperative Pain in Patients Undergoing Laparoscopic Cholecystectomy

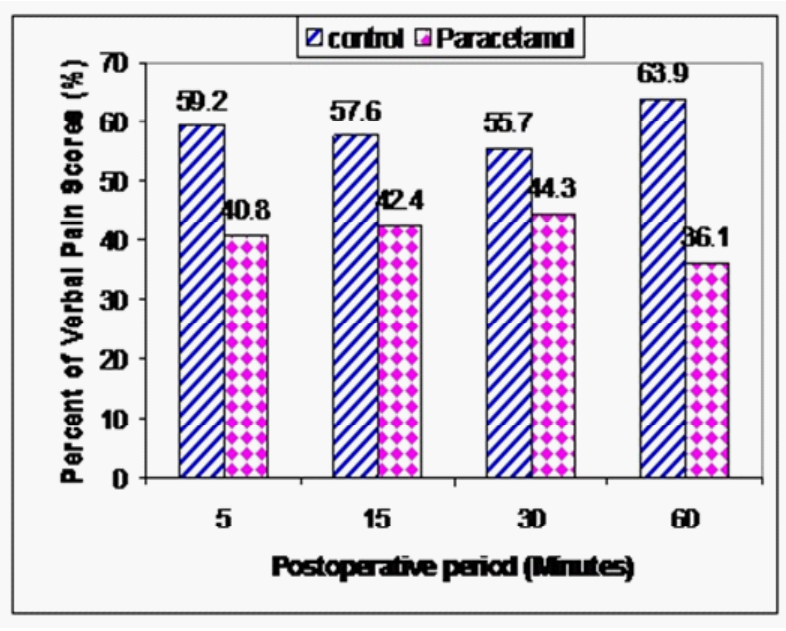

Figure 2. Comparison of Percent of verbal pain scores in control and paracetamol groups at early postoperative period

\section{DiscusSION}

Inflammation progresses after cholecystectomy at the operation side, the diaphragm, and the peritoneum. This process triggers nausea and postoperative pain, which is sensed on epigastrium or right shoulder especially early period of the surgery [34].

Long acting analgesic administration or preoperative analgesic administration could reduce postoperative pain [35].

Intravenous paracetamol is a fast and effective agent that could support the effects of opioids with fewer side effects such as non steroid anti-inflammatory drugs which causes gastrointestinal hemorrhage, hematologic disturbances, and renal dysfunction [36, 37].

Effect of paracetamol after laparoscopic cholecystectomy was evaluated and it has been suggested that paracetamol was effective for pain after laparoscopic cholecystectomy. Several studies have been in agreement with our findings [33, 37-39].

These are the factors reducing hospital stay and costs because of the economical necessities. Beside its effective analgesic properties, paracetamol administration during pre-operative period could support effective and faster recovery by reducing morphine requirement and duration of staying in recovery room this is in agreement with Salihoglu et al. [39].

\section{CONCLUSION}

It can be concluded that paracetamol is effective postoperative analgesia. It is the drug of choice in patients that cannot be treated with non-steroidal antiinflammatory drugs. Pre-operative administration of paracetamol supports effective and faster recovery. Anticipatory guidance should be provided to encourage to use paracetamol as postoperative analgesia. Further studies are needed to clarify the postoperative recovery characteristics by Modified Aldrete's Scoring System.

\section{REFERENCES}

[1] Litwin DE, Cahan MA. Laparoscopic cholecystectomy. Surg Clin North Am. 2008; 88(6): 1295-313.

[2] National Institutes of Health (NIH). Gallstones and Laparoscopic Cholecystectomy. NIH Consensus Statement. NIH. 1992; 14-16.

[3] Calland JF, Tanaka K, Foley E, Bovbjerg VE, Markey DW, Blome S, et al. Outpatient laparoscopic cholecystectomy: patient outcomes after implementation of a clinical pathway. Ann Surg. 2001; 233(5): 704-715.

[4] Shea JA, Berlin JA, Bachwich DR, Staroscik RN, Malet PF, McGuckin M. Indications for and outcomes of cholecystectomy: a comparison of the pre and postlaparoscopic eras. Ann Surg. 1998; 227(3): 343-350

[5] Potts JR 3rd. What are the indications for cholecystectomy?. Cleve Clin J Med. 1990; 57(1): 40-47.

[6] Gupta SK, Shukla VK. Silent gallstones: a therapeutic dilemma. Trop Gastroenterol. 2004; 25(2): 65-68.

[7] Lo CM, Liu CL, Fan ST, Lai EC, Wong J. Prospective randomized study of early versus delayed laparoscopic cholecystectomy for acute cholecystitis. Ann Surg. 1998; 227(4):461-467.

[8] Willsher PC, Sanabria JR, Gallinger S, Rossi L, Strasberg S, Litwin DE. Early laparoscopic cholecystectomy for acute cholecystitis: a safe procedure. J Gastrointest Surg. 1999; 3(1): 50-53.

[9] Pessaux P, Tuech JJ, Rouge C, Duplessis R, Cervi C, Arnaud JP. Laparoscopic cholecystectomy in acute 
Evaluation of Intravenous Paracetamol Administration on Postoperative Pain in Patients Undergoing Laparoscopic Cholecystectomy

cholecystitis. A prospective comparative study in patients with acute vs. chronic cholecystitis. Surg Endosc. 2000; 14(4): 358-361.

[10] Uhl W, Müller CA, Krähenbühl L, Schmid SW, Schölzel S, Büchler MW. Acute gallstone pancreatitis: timing of laparoscopic cholecystectomy in mild and severe disease. Surg Endosc. 1999; 13(11): 1070-1076.

[11] Curro G, Baccarani U, Adani G, Cucinotta E. Laparoscopic cholecystectomy in patients with mild cirrhosis and symptomatic cholelithiasis. Transplant Proc. 2007; 39(5): 1471-1473.

[12] Cucinotta E, Lazzara S, and Melita G. Laparoscopic cholecystectomy in cirrhotic patients. Surg Endosc. 2003; 17(12): 1958-1960.

[13] SteinerCA,BassEB,TalaminiMA,PittHA,Steinberg EP. Surgical rates and operative mortality for open and laparoscopic cholecystectomy in Maryland. N Engl J Med. 1994; 330(6): 403-408.

[14] Csikesz N, Ricciardi R, Tseng JF, Shah SA. Current status of surgical management of acute cholecystitis in the United States. World J Surg. 2008; 32(10): 2230-2236.

[15] Giger UF, Michel JM, Opitz I, Th Inderbitzin D, Kocher T, Krähenbühl L. Risk factors for perioperative complications in patients undergoing laparoscopic cholecystectomy: analysis of 22,953 consecutive cases from the Swiss Association of Laparoscopic and Thoracoscopic Surgery database. J Am Coll Surg. 2006; 203(5): 723-728.

[16] Bunchorntavakul C, Reddy KR. Acetaminophenrelated hepatotoxicity. Clin Liver Dis 2013; 17:587.

[17] Lee, WM. "Acetaminophen (APAP) hepatotoxicityIsn't it time for APAP to go away?". Journal of hepatology. 2017; 67 (6): 1324-1331.

[18] Perrott D. A., Piira T., Goodenough B., \& Champion G. D. Efficacy and safety of acetaminophen vs ibuprofen for treating children's pain or fever: a meta-analysis. Archives of pediatrics \& adolescent medicine, 2004; 158(6): 521-526.

[19] Russell FM, Shann F, Curtis N, Mulholland K. "Evidence on the use of paracetamol in febrile children". Bulletin of the World Health Organization. 2003; 81 (5): 367-372.

[20] Hosseini Jahromi SA, Hosseini Valami SM, Hatamian S. Comparison between effect of lidocaine, morphine and ketamine sprayon posttonsillectomy pain in children. Anesth Pain. 2012; 2(1): 17-22

[21] Imani F, Safari S. Pain relief is an essential human right", We should be concerned about it. Anesth Pain. 2011; 1(2): 55-57

[22] Imani F, Rahimzadeh P. Gabapentinoids: Gabapentin and pregabalin for postoperative pain management. Anesth Pain. 2012; 2(2): 52-53.

[23] Imani F, Rahimzadeh P, Faiz SHR. Comparison of the efficacy of adding clonidine, chlorpromazine, promethazine, and midazolam to morphine pumps in postoperative pain control of addicted patients. Anesth Pain. 2011; 1(1): 10-14

[24] Shoar S, Esmaeili S, Safari S. Pain management after surgery: A brief review. Anesth Pain. 2012; 1(3): 184-186

[25] Hosseini Jahromi SA, Sadeghi poor S, Hosseini Valami SM, Javadi A. Effects of suppository acetaminophen, bupivacaine wound infiltration, and caudal block with bupivacaine on postoperative pain in pediatric inguinal herniorrhaphy. Anesth Pain. 2012; 1(4): 243-247

[26] Imani F. Postoperative pain management. Anesth Pain. 2011; 1(1): 6-7

[27] Alimian M, Imani F, Faiz SHR, Pournajafian A, Navadegi SF, Safari S. Effect of oral pregabalin premedication on post-operative pain in laparoscopic gastric bypass surgery. Anesth Pain. 2012; 2(1):12-16

[28] Lee RM, Tey JBL, Chua NHL. Postoperative pain control for total knee arthroplasty: continuous femoral nerve block versus intravenous patient controlled analgesia. Anesth Pain. 2012; 1(3):184-186

[29] Hurley RWWCC. Acute Postoperative Pain. In: Miller RD, Eriksson LI, Fleisher LA, WienerKronish JP, Young WL, editors. Miller's Anesthesia. $7^{\text {th }}$ ed. USA: Churchill Livingstone; 2010. p. 2763 
Evaluation of Intravenous Paracetamol Administration on Postoperative Pain in Patients Undergoing Laparoscopic Cholecystectomy

[30] Chandrasekharan NV, Dai H, Roo s KL. Cox-3 a cyclo oxygenase- 1 varient inhibited by acetaminophen and other analgesic antipyretic drugs. Proc Natl Acad Sci. 2002; 99: 1326-1329.

[31] Bakshi SG. Efficacy of Additives to Morphine Pumps in Post-Operative Pain Control of Addicted Patients. Anesth Pain. 2011; 1(2): 103-104.

[32] Duncan GH, Bushnell MC, Lavigne GJ. Comparison of verbal and visual analogue scales for measuring the intensity and unpleasantness of experimental pain. Pain, 1989; 37: 295-303.

[33] Macario, A., \& Royal, M. A. A literature review of randomized clinical trials of intravenous acetaminophen (paracetamol) for acute postoperative pain. Pain Practice, 2011; 11(3):

[34] Narchi P, Benhamou D, Fernandez $H$. Intraperitoneal local anesthetic for shoulder pain after day case laparoscopy. Lancet., 1991; 38: 8782-8783.

[35] Wall PD. The prevention of postoperative pain. Pain. 1988; 33:289-290.

[36] Power I. Recent Advances in postoperative pain therapy. Br J Anaesth. 2005;43-51.

[37] Herna' ndez-Palazo' n J, Tortosa JA, Martı́nezLage JF, et al. Intravenous administration of propacetamol reduces morphine consumption after spinal fusion surgery. Anesth Analg. 2001; 92:1473-76.

[38] Sharma R., Gupta R., Choudhary, R., \& Bajwa, S. J. S. Postoperative analgesia with intravenous paracetamol and Dexmedetomidine in laparoscopic cholecystectomy surgeries: a prospective randomized comparative study. International Journal of Applied and Basic Medical Research, 2017; 7(4), 218-22.

[39] Salihoglu Z., Yildirim, M., Demiroluk, S., Kaya, G., Karatas, A., Ertem, M., \& Aytac, E. Evaluation of intravenous paracetamol administration on postoperative pain and recovery characteristics in patients undergoing laparoscopic cholecystectomy. Surgical Laparoscopy Endoscopy \& Percutaneous Techniques, 2009; 19(4), 321-323.]

Citation: Abdalssalam Abdelhamid Alahresh, Azab Elsayed Azab, et al. Evaluation of Intravenous Paracetamol Administration on Postoperative Pain in Patients Undergoing Laparoscopic Cholecystectomy. Archives of Anesthesiology. 2020; 3(2): 07-13

Copyright: (c) 2020 : Abdalssalam Abdelhamid Alahresh, Azab Elsayed Azab, et al. This is an open access article distributed under the Creative Commons Attribution License, which permits unrestricted use, distribution, and reproduction in any medium, provided the original work is properly cited. 